\title{
Prostituição de travestis na Baixada Cuiabana: hierarquização, territorialização e dissidências de gênero com base em uma perspectiva (des)centrada'
}

Moisés Lopes ${ }^{2}$

Haydeé Tainá Schuster ${ }^{3}$

Resumo: Este trabalho visa a analisar dados etnográficos que tratam da performance de gênero de travestis que trabalham com prostituição na baixada cuiabana. Após a apresentação do território do Zero, entraremos nas questões voltadas para os fluxos e contrafluxos dos itinerários que as travestis fazem do interior do estado para a capital e vice-versa e de como isso influencia na hierarquização interna entre as travestis Tops, travestis e bichas. Ao analisar esses aspectos, percebemos algumas dissidências entre as travestis com maior status social e as recém-chegadas do interior.

Palavras-chave: Travestis; micropolítica; antropologia urbana; Baixada Cuiabana.

Transvestite prostitution in the Baixada Cuiabana: hierarchization, territorialization and gender dissidences from a (de) centered perspective

Abstract: This paper aims to analyze ethnographic data that deal with the gender performance of transvestites who work with prostitution in the Cuiabana lowland. After

1 Agradecemos ao financiamento por meio de bolsa de mestrado da CAPES - Coordenação de Aperfeiçoamento de Pessoal de Nível Superior.

2 Universidade Federal de Mato Grosso (UFMT) - Cuiabá - Brasil - sepolm@gmail.com

3 Universidade Federal de Mato Grosso (UFMT) - Cuiabá - Brasil - haydeeschuster@gmail.com 
the presentation of the territory of Zero, we will address the issues related to the flows and counterflows of the travestis routes from the interior of the state to the capital and vice versa and how this influences the internal hierarchy between the travestis Tops, travestis and rows. In analyzing these aspects, we noticed some dissent between the transvestites with higher social status and the new arrivals from the interior.

Keywords: Transvestites; micropolitics; urban anthropology; Baixada Cuiabana.

\section{INTRODUÇÃO}

O Zero é uma região localizada na cidade de Várzea Grande, no estado de Mato Grosso, que possui em torno de seis (6) quadras que diuturnamente recebem mulheres cisgêneras e travestis. Várzea Grande é uma cidade que faz divisa com a capital Cuiabá, contudo, preserva um ar interiorano. Sendo separados por apenas uma ponte, o intercâmbio de pessoas é bastante intenso durante $o$ dia, a exemplo das próprias trabalhadoras da região que realizam todos os dias esse trajeto por morarem em Cuiabá.

Por esse motivo, o Zero torna-se um território bastante complexo e organizado em suas leis e hierarquia, principalmente no que diz respeito à divisão territorial, bastante incisiva em relação aos acordos internos. O Zero expressa, por si só, imaginários sociais acerca da prostituição, tráfico de drogas e violência e as travestis são algumas das protagonistas desses imaginários. O nome do "Zero" nunca passa despercebido para o ouvinte que já tem uma impressão do que a região significa.

Com essa organização interna entre travestis e Estado, travestis e Polícia, travestis e mulheres cis, travestis e travestis, o foco se remete nesse artigo ao último termo supracitado: travestis e travestis, que chamamos nesse contexto de intra-hierarquia. É interessante refletir acerca das palavras utilizadas para descrever determinados conceitos, uma vez que tanto intra-hierarquia quanto dissidências possuem seus propósitos nesse contexto exposto.

O contexto no qual as relações entre as travestis do Zero ocorrem é influenciado por diversas relações de oposição e afinidades, seja por meio das relações entre as trabalhadoras do Zero (internas); ou entre elas e os agentes do Estado (externas); a origem das travestis (outras capitais ou interior do estado); e suas modificações corporais (irreversíveis ou não), todas estas relações produzem e influenciam na produção da performance de gênero bem como se mostra também intimamente ligada a quais ruas do Zero estas travestis "pertencem" para fazer ponto. 
Por isso, a palavra intra parece caber tão bem aqui. Enquanto em alguns momentos as relações são tensionadas com os agentes externos ao Zero, em contrapartida, as relações internas se colocam 24 horas em tensionamento, tal como observamos nas falas de nossas interlocutoras, uma vez que além dos pontos no Zero, as travestis costumam dividir a mesma pensão como moradia. O prefixo intra pode ser compreendido para além do significado "dentro", estendendo-se a um sinônimo interessante: no interior. É uma questão tanto de interior das relações entre as travestis e seus pares, quanto uma questão de geografia: interior e cidade grande.

A outra palavra designada para essa análise do material etnográfico ${ }^{4}$ é dissidências. Essa palavra em geral refere-se à uma discordância de uma política comum manifesta, poder instituído ou decisão coletiva. Enquanto as travestis que trabalham no Zero são consideradas dissidentes de um sistema político heteronormativo, consideradas uma minoria, elas também se organizam em camadas e instituem conceitos e normativas a serem seguidas para manter a ordem da ocupação do espaço. As travestis mais velhas, como será melhor detalhado a seguir, determinam quais bichas podem se tornar travestis, se inserindo no sistema de relações; e, as que não podem, por não serem concordantes com o sistema de ocupação territorial, modificação corporal e de conjunto de comportamentos a serem seguidos, sendo consideradas, por conta disso, dissidentes.

A heterossexualidade compulsória aparece muito nas questões que permeiam o Zero, principalmente com as travestis que estão nos limites periféricos do Zero. Sedgwick (1985) aponta que as relações sociais não diferem do ordenamento das categorias sexuais. A heterossexualidade então, pode ser expressa como algo natural e que reproduz um aparato de ordenação de desejos que perpassam inclusive os "dissidentes" deste aparato de controle, recaindo tanto sobre a questão da homossexualidade quanto sobre a questão da travestilidade.

Por justamente serem dissidentes do sistema heteronormativo e dissidentes de sua própria intra-hierarquia, as travestis interioranas deparam-se com uma

Trata-se de pesquisa realizada entre os anos de 2017 e 2018 por meio de etnografia realizada no Zero e em outros espaços da cidade e que se encontra de modo mais longamente detalhado na dissertação intitulada "A dona da rua: territorialização e performance de gênero a partir da prostituição de travestis na Baixada Cuiabana” desenvolvida por Haydeé Tainá Schuster junto ao Programa de Pós-Graduação em Antropologia Social da Universidade Federal de Mato Grosso sob orientação de Moisés Lopes. Outrossim, é importante ressaltar que parte das discussões desenvolvidas neste artigo fazem parte também do projeto de pesquisa intitulado "Violências, resistências e subjetividades de travestis e transexuais na Baixada Cuiabana" coordenado por Moisés Lopes, bem como, finalizando, é importante ressaltar que uma parte das discussões também advém da observação participante de Moisés Lopes junto ao Conselho Municipal de Atenção à Diversidade Sexual de Cuiabá (CMADS) desenvolvida simultaneamente como pesquisador e conselheiro eleito representando a UFMT. 
série de fatores que vão desde o deslumbre que a capital oferece tanto com um número maior de travestis que no interior - com isso, poderiam oferecer algum tipo de relativa segurança para viver, bem como, em conjunto com o acesso facilitado a certos bens de consumo como roupas, maquiagem e salão de beleza - quanto com a maior "oferta de serviços oficiais e não oficiais" que envolvem as próprias modificações corporais. Em contrapartida, deparam-se constantemente também com uma reprodução de relações de poder entre seus pares e se vêm num complexo sistema de relações interpessoais que são permeadas pela ocupação de territórios e pela performance de gênero.

O Zero também é um território que não se fecha em si mesmo, apesar da intra-hierarquia ser bastante rígida, os componentes que estão nos liminares hierárquicos considerados superiores e inferiores, transitam entre outras redes urbanas. Por isso, é necessário ao pesquisar um território, tomar cuidado com o que Magnani (2003) descreve: "a tentação de transformar a cidade em pequenas aldeias, fechadas em si mesmas". As travestis não vivem isoladas ali, elas não formam "uma aldeia", elas circulam entre outras capitais e as travestis do interior do Estado chegam até o Zero também com algumas expectativas que podem ser supridas, enquanto outras nem tanto.

Os tópicos abordados nesse trabalho são voltados, então, para o recorte de alguns pontos que o Zero nos faz refletir acerca dessas intra-relações e dissidências sexuais. Inicialmente, se faz necessário apresentar o Zero em suas relações e singularidades. Após essa apresentação geral, entraremos nos itinerários e fluxos que as travestis do Zero realizam no estado de Mato Grosso e de como isso influencia nas colocações das mesmas no espaço. Por conseguinte, relacionamos essas origens geográficas com as colocações nos espaços, a intra-hierarquia e a performance de gênero. Finalizando, apresentamos uma série de questionamentos provocativos sobre a produção de uma "outra-ordem" paralela a ordem heterocentrada e protagonizada por um grupo de travestis que ocupam o território do Zero, uma região tomada como marginalizada, mas que recebe fluxos de travestis de diversos lugares e capitais do país por ser considerado um local "seguro" e "bem-estruturado" para a prática da prostituição.

\section{ZERO E SUAS PECULIARIDADES}

O Zero é um território extremamente organizado em suas hierarquias e leis, vigiadas pelos seguranças particulares dos donos de comércio dali e das donas de pensão. Não existe diferença nítida de movimentação do comércio do sexo no período do dia e da noite. Apesar de algumas mudanças irem 
ocorrendo no passar das horas do dia, por conta dos outros comércios da região e das crianças que passam para ir à escola, o acordo é que a roupa seja comedida enquanto o dia esteja claro, não fiquem nuas ou abordem pessoas que passam nas ruas.

Contudo, a prostituição ocorre ali independente do horário. Tanto Pelúcio (2009), quanto Benedetti (2005) mostram em suas etnografias uma diferença entre o mesmo espaço durante o dia e a noite, um território cheio de comércios e pessoas que passam por ali, que vai se modificando conforme o sol se põe e dando lugar as garotas, travestis e michês que vão aparecendo. No Zero, diferentemente, comerciantes, pessoas que passam, moradores, motéis, crianças, bares, pensões, travestis e garotas estão simultaneamente ocupando o mesmo espaço.

No Zero, em um primeiro momento, as travestis possuem o discurso de que não há agenciadores, ou donos de rua, que elas trabalham para si mesmas, mas basta um pouco mais de conversa para que elas digam que a dona da pensão é também a dona dos pontos e que essa figura é essencial para manter a ordem do espaço e garantir a segurança delas.

De Certeau (1998) explica que a ordem espacial organiza um conjunto de possibilidades, que correspondem a práticas do espaço e a uma base da ordem do território construído:

Um indício das relações que as práticas do espaço mantêm com essa ausência [de lugar] é precisamente mantida pelos seus jogos sobre e com os nomes. $\mathrm{O}$ espaço pode abarcar experiências espaciais distintas, que pode ser compreendido através das "ações narrativas" (De Certau, 1998: 202).

São essas "ações narrativas" que exprimem práticas organizadoras do espaço. Essas práticas organizadoras de espaço e de performances se mostram no campo por meio de um diálogo realizado e acordado entre mulheres cisgênero e travestis que dividem o território e que regulamentam as práticas de trabalho e de gênero. Esse acordo é bem objetivo e deve ser cumprido para que ambas não entrem conflito na região, o que é considerado péssimo para a reputação do lugar, uma vez que quanto mais perigosas elas forem consideradas, menos clientes aparecem. Com base nessas práticas organizadoras é que a territorialização acontece.

Uma das principais informantes nessa pesquisa foi Dani, travesti que trabalha no Zero há quatro (4) anos e já fez as devidas modificações necessárias para estar na primeira rua do Zero, ou na Rua das Tops. Segundo Dani, essa 
hierarquia que foi legitimada pelo Estado ${ }^{5}$ e este acordo serve para que "as mais bonitas fiquem no claro e as mais feias no escuro", demarcando a diferença entre elas e as ruas, entre claro e escuro, entre quem fica em pé na calçada e quem pode sentar-se na cadeira e esperar que algum cliente apareça. É também este acordo de uso do espaço que diz quem elas são, uma vez que ocupar certos lugares e ruas demonstram na hierarquia, se são "tops" ou não e também fala sobre o tráfico de drogas na região. Isso começará a ficar mais claro com o passar das apresentações das ruas.

Ser "Top" se tornou uma gíria não somente usada pelas travestis, mas em geral por jovens, que significa algo que todos apreciam com empolgação, como algo mais valioso, de um status superior. Neste contexto analisado, pode se aplicar também para se referia a uma rua que abriga as travestis de maior prestígio: "as gatas", que adquirem esse um maior valor simbólico e concreto por meio de alguns requisitos como a modificação corporal, aparência mais próxima possível à feminina, além do tempo de trabalho na região e reconhecimento pelos seus pares. Ser "Top" possibilita que a travesti poderá, futuramente, vir a ser uma dona de pensão: o maior status dentro da hierarquia no Zero.

Um outro ponto interessante de se destacar é que quando se trata da circulação de pessoas de maneira constante, somente pessoas autorizadas podem adentrar ao Zero, qualquer movimentação diferente, é avisada diretamente a quem cuida do ponto por meio de vigilantes particulares que rondam a região. Este guarda, segundo as travestis, é contratado pela dona de pensão mais conhecida da região em conjunto com os donos dos motéis para resguardá-las dos perigos que a rua oferece. Normalmente, é um homem (mesmo que sejam outros homens que representem o perigo para elas), que fica rondando em baixa velocidade de moto, observando o movimento e relatando caso algo incomum aconteça.

Para além dos motéis, bares e boates, a região possui comércios e residências mais antigas. As kitnets servem de moradia para quem trabalha na região e as casas são de famílias que também são de antigos moradores, que vivem ali

5 Em 2008, ocorreu um grande acordo entre a representante das travestis no Zero, Lilith e outras que a acompanhavam e a polícia militar, intermediada pelo então "Centro de Referência de Enfrentamento à homofobia” que se instituiu toda essa organização pela qual o Zero é conhecido. Nessa reunião, se elaborou o que passou a ser intitulado como "Pacto de Conduta entre as Profissionais do Sexo - Travestis e Agentes de Segurança Pública do Estado de Mato Grosso", mediada pelo Centro de Referência em Direitos Humanos e Prevenção e Combate a Homofobia (CRDH), que existiu entre os anos de 2008 e 2012, sendo incorporado atualmente à Secretaria de Direitos Humanos, estavam presentes alguns agentes de Segurança Pública, da Saúde, a ANTRA - Associação Nacional das travestis e a ASTRA/MT Associação das Travestis do Estado de Mato Grosso. Foram realizadas oficinas, palestras e grupos de trabalho visando a prevenção de DSTs (Aragusuku; Lopes, 2016). 
desde antes de virar um famoso ponto de prostituição. É um limiar entre o doméstico, familiar e a vida noturna que envolve o bar e os motéis. Como também ocorre prostituição durante o dia, há um acordo tácito de nenhuma delas fazer ponto em frente às casas de família. As travestis sempre comentam desse limite em relação ao âmbito doméstico: "Eu vivo falando pras meninas não ficarem sem roupa durante o dia, principalmente com os peitos de fora. Ali tem muita casa de gente de família, crianças que passam pra ir pra escola. Precisamos respeitar esse ambiente durante o dia, mas elas não tão nem aí, acham que podem ficar destruindo a família dos outros, mostrando o corpo de qualquer jeito pra rua epra quem passar, sem limites mesmo que haja crianças" comentou Ariane, uma travesti que faz ponto na região há algum tempo e ajuda outras travestis. Ariane fica na rua das "Tops" e está sempre viajando e fazendo ponto em outros lugares.

A rua, como descreve DaMatta (1997), é o lugar do perigo e do não pertencimento, um lugar de fluxos e de passagem. Já para as travetis que estão no Zero, a rua pode representar simultaneamente o perigo, mas também, representa o lugar de trocas, sociabilidades e oportunidades. DaMatta (1997) escreve justamente sobre essa contrapartida entre o âmbito público e o privado, a casa e a rua, mostrando que estes não são somente espaços geográficos, mas sim entidades que se ligam a sentimentos, reações, leis e emoldurações estéticas próprias. Limpamos a casa e jogamos a sujeira na rua, que se torna pública, onde todos passam e ao mesmo tempo, se torna responsabilidade do Estado. Na rua, a vergonha e a desordem é do Estado. A casa é sempre dotada de cunho moral e idealista, enquanto a rua mistura a não responsabilidade pelo que passa e a rejeição do que não tem pertencimento a lugar algum.

No entanto, o público e o privado se desloca no Zero, uma vez que a rua para as travestis é parte do âmbito doméstico e privado, já que existe uma organização, ordem, hierarquia e o essencial para o âmbito privado que é o pertencimento ao local. A própria pensão onde vivem não representa tanto o âmbito privado como a casa a priori representaria. Isso se deve pois as travestis não se sentem seguras na pensão, não existe a sensação de pertencimento e estão suscetíveis ao roubo das colegas de quarto, vivendo sempre sob ameaça.

Essas outras personagens são travestis que vem de outras cidades, tanto do interior do Mato Grosso, sendo as mais comuns de Rondonópolis, quanto dos estados vizinhos, como Rondônia, Pará, Mato Grosso do Sul e região Nordeste. Essas travestis que chegam para "fazer ponto", se não estiverem instaladas em pensões de travestis conhecidas, podem ser postas para fora do Zero diante de violência física. É necessário que se pague para descer no ponto ou que alugue um apartamento para trabalhar. 
Assim, existe uma diferença entre a prostituição no Zero e a prostituição em Cuiabá. Essa diferença foi bastante pontuada na entrevista com o psicólogo da coordenadoria de combate a DSTs de Cuiabá, que lida diariamente com profissionais do sexo tanto do Zero quanto de Cuiabá, uma vez que mesmo as que trabalham em Várzea Grande moram em Cuiabá e usam os serviços de saúde da capital. A principal diferença entre as narrativas delas está no fato de que apesar do Zero ser considerado "esquecido pelo Estado" no que se refere às políticas públicas, ainda sim, ele é extremamente estruturado e hierarquizado. É um território organizado pelas pessoas que trabalham ali e utilizam dele. Existem leis e códigos internos, seguidos rigorosamente para o bom funcionamento. Já em Cuiabá os pontos de prostituição são dispersos entre as esquinas, como apontou Gabriel: "é um lugar sem lei. Tudo é possivel. Tudo acontece, sem que ninguém vigie e nem que ninguém saiba ou proteja os seus".

É bastante comum casos de travestis que saem de casa e preferem mudar-se de cidade e para isso, buscam auxílio em grupos do Facebook, no qual trocam informações sobre quais capitais e espaços de prostituição haveria mais chances para crescimento financeiro, por isso já chegam em Várzea Grande com contato de onde vão ficar e a quem devem pagar para descer no ponto. A notícia a seguir demonstra um pouco sobre o Zero ser "referência" para essas travestis de outras cidades:

\section{$\leftarrow \rightarrow \circlearrowright \mid$ olivre.com.br/zero-km-se-torna-referencia-como-ponto-de-prostituicao-no-brasil}

\section{"Zero km" se torna referência como ponto de prostituição no Brasil}

L Redação/ pautas@olivre.com.br

30/09/2017 às 07:00

Um quarteirão em forma de quadrado, rodeado por bares e motéis e repleto de pessoas cuja profissão é a prostituição, assim poderia ser resumido o Zero km, em Várzea Grande.

Mas não é apenas isso, nesse lugar há vidas repletas de histórias, que vão além das roupas curtas e dos olhares convidativos de cada uma das mulheres ali presentes.

A reportagem do $\mathrm{O}$ Livre conversou com cinco garotas de programa - quatro mulheres, sendo uma transexual, e uma travesti - e descobriu que o Zero se tornou referência como ponto de prostituição no Brasil.

Das cinco entrevistadas, três não são de Mato Grosso e todas, por unanimidade, afirmaram que preferem trabalhar no Zero, porque consideram um local sequro para a

Imagem 1: Notícia sobre o Zero. Fonte: Jornal O livre. Disponível em: <https://www. olivre.com.br/zero-km-se-torna-referencia-como-ponto-de-prostituicao-no-brasil/>. Acesso em: 07 abr. 2020. 
Pensando acerca desse panorama construído sobre o Zero, podemos dizer que o território se trata de uma mancha (Magnani, 2012). Um lugar que, apesar de parecer heterogêneo num primeiro momento, com pessoas distintas dividindo o mesmo espaço, homens, mulheres cisgênero, travestis, donos de bares e motéis, acolhe a todos. Esse encontro momentâneo em um lugar ocorre, pois, os objetivos são compartilhados: tudo gira em torno da prostituição, diretamente ou indiretamente A mancha é um território de acolhimento, que independe de fatores morais, diferenças sociais ou raciais. Por mais que territórios como o Zero, pareçam hostis e perigosos, no fundo são lugares que mais possibilitam o acolhimento de pessoas consideradas dissidentes.

Por isso, o Zero se faz tão diferente de outras capitais: os pontos são diuturnos, as paisagens diurnas mesclam-se com as mulheres cisgêneras e travestis que trabalham ali, sua organização é bastante delimitada, existem os protocolos de comportamento e divisão territorial, relativa segurança interna. Além disso, o Zero não está necessariamente localizado na capital do estado, mas numa cidade que compartilha o limite. O Zero também é fruto de itinerários de vai e vem fazendo parte de um circuito nacional entre as capitais e de um circuito dentro do próprio estado.

\section{"CIRCUITOS INTERIORANOS"}

Outra maneira de fazer etnografia e identificar territórios e espaços, percebendo os códigos compartilhados é por meio de mapas sensoriais. Um mapa sensorial contém diversas atribuições de sentidos simbólicos e corporais e demonstra essa organização das identidades imersas no espaço. Não estamos sobre um mapa, caminhando num único plano, mas sim imersos no espaço, e até certo ponto o espaço também está imerso em nossos corpos. Um mapa contém muito mais que pura geografia, está repleto de sinais e marcadores políticos, que dividem e segregam, que atribuem características e adjetivos. Não somos pássaros que sobrevoam os locais e olham de cima a paisagem (Ingold, 2005). Fazemos parte da paisagem, modificamo-las com nossa simples presença e ela nos modifica na medida em que nos refazemos constantemente (Ingold, 2005).

A única maneira de se construir um mapa é andando por ele. Tim Ingold (2005) faz algumas reflexões sobre mapas geográficos e cognitivos, sendo que os mapas constroem-se primeiramente na memória de quem os desenha e nas sensações de quem caminha por ele. Por isso que, ao se perguntar a uma 
interlocutora da região: "onde você faz ponto?", a possível resposta não está no nome de uma rua, mas na ordem hierárquica da ruas das tops, algo do tipo "na primeira rua do zero" ou "na rua do Star Night". É, neste sentido, que "os espaços não possuem posição, possuem história” (Ingold, 2005: 77). Por isso, os espaços não existem num mapa, mas no que Tim Ingold nomeia de matriz-movimento. Essa habilidade em situar-se na região e mover-se pelos caminhos sem se perder é possível, pois o nativo está inserido "dentro de um contexto histórico de jornadas efetuadas anteriormente" (Ingold, 2005: 78). Por isso, um mapa nativo é antes de tudo, um mapa afetivo. O mapa é feito de imagens mentais que mudam conforme nos movimentamos no espaço. A seguir, uma foto da rua na qual as bichas/gays que recém chegam do interior costumam fazer ponto:

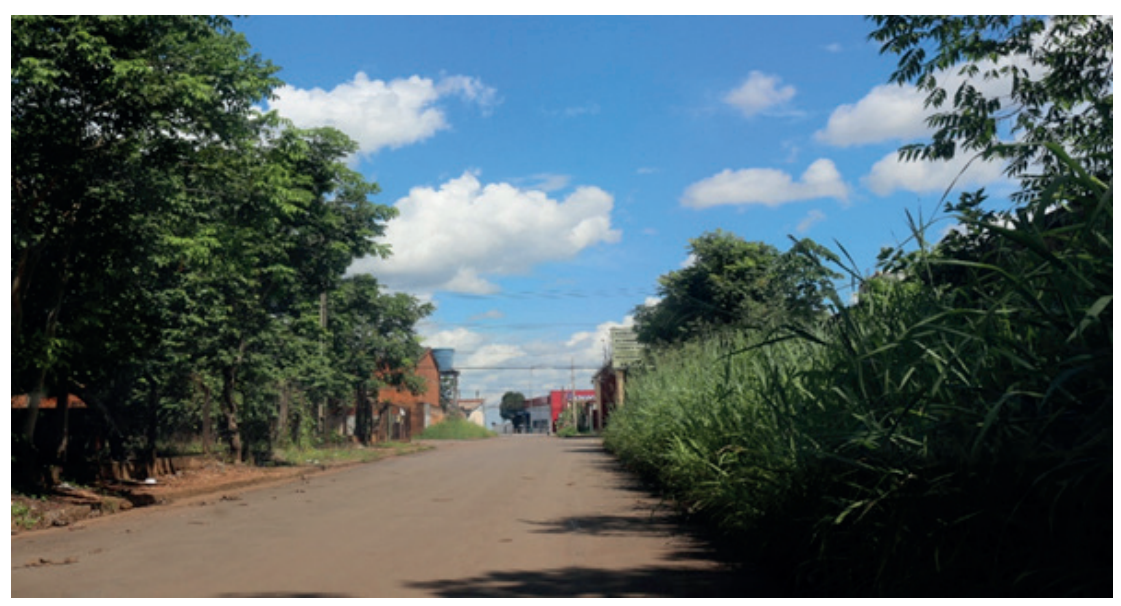

Imagem 2: Rua das bichas. Fonte: acervo pessoal.

São olhares que vão para lugares que criam sentimentos e sensações a quem caminha, um trajeto como descrito por Magnani (2012), sendo o caminho percorrido que ligam manchas a pedaços, podendo ser complementares ou alternativos. São as ruas escuras das bichas que se escondem entre o matagal. São os terrenos baldios que acumulam água e que servem de ponto de encontro para negociar programas. São os bares que tocam música alta e possuem aquele jogo de luz cheios de informações. Esse "trajeto" realizado entre os "pedaços" é feito somente por pessoas autorizadas, pois, caso uma travesti vá para um "pedaço" que as mulheres fazem ponto, certamente

6 É comum a utilização de bares e motéis como referência de localização do ponto de prostituição. 
haverá briga - e é nessas horas que as travestis se vangloriam de sua força física "masculina".

No que diz respeito à intra-hierarquia, as travestis se dividem entre as bichas, que iniciaram sua transição e ainda transitam entre uma performance de gênero masculina e feminina, começaram recentemente a trabalhar no Zero e ficam numa rua mais escura, "cheia de mato". Por conseguinte, subindo na categoria, as travestis que iniciaram sua transição e começaram a trabalhar com prostituição "de maneira séria". Segue uma foto de uma das ruas que as travestis Tops fazem ponto:

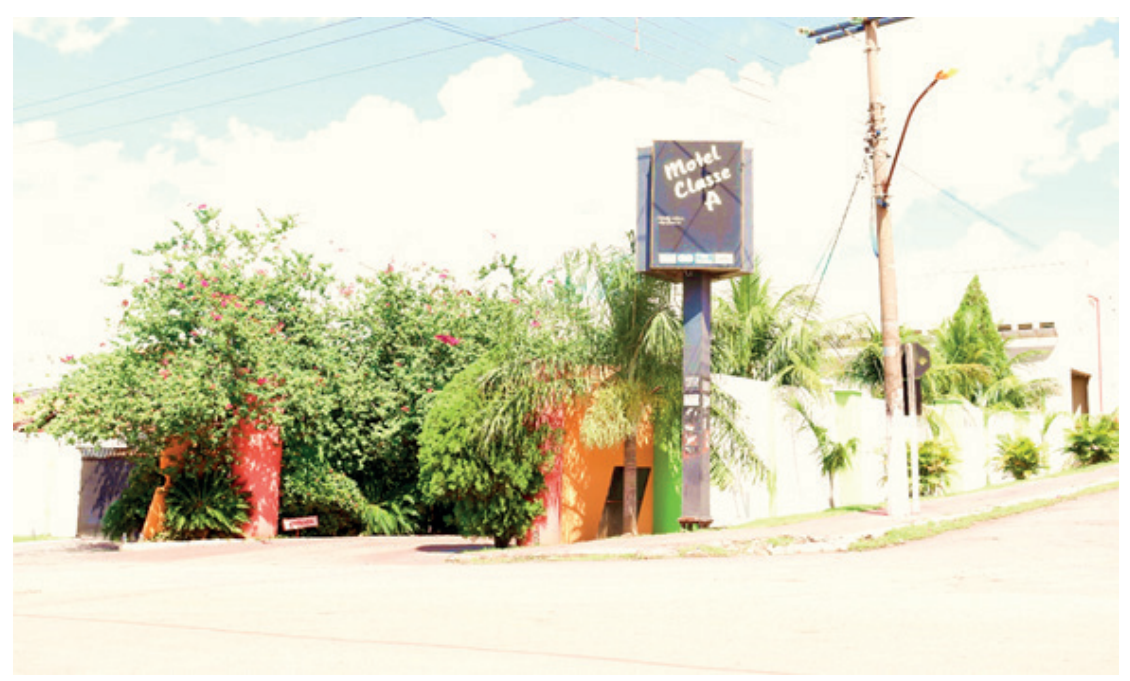

Imagem 3: Rua das Tops. Fonte: acervo pessoal.

Após isso, as Travestis Tops que organizam o espaço em nome da dona da pensão e estão na primeira rua do Zero, estas já fizeram muitas modificações corporais e são consideradas porta-vozes oficiais das informações sobre o Zero, determinando inclusive quem é considerada travesti ou não. E no limiar, a dona da pensão, uma travesti mais antiga que detém uma pensão e que também corresponde aos cuidados e uso dos pontos sob sua responsabilidade no Zero.

Quanto aos fluxos migratórios, segue o mapa do Mato Grosso que identifica alguns deles. Logicamente que algumas travestis podem vir de outras cidades, contudo, as mais citadas e pontuadas aparecem no mapa a seguir: 


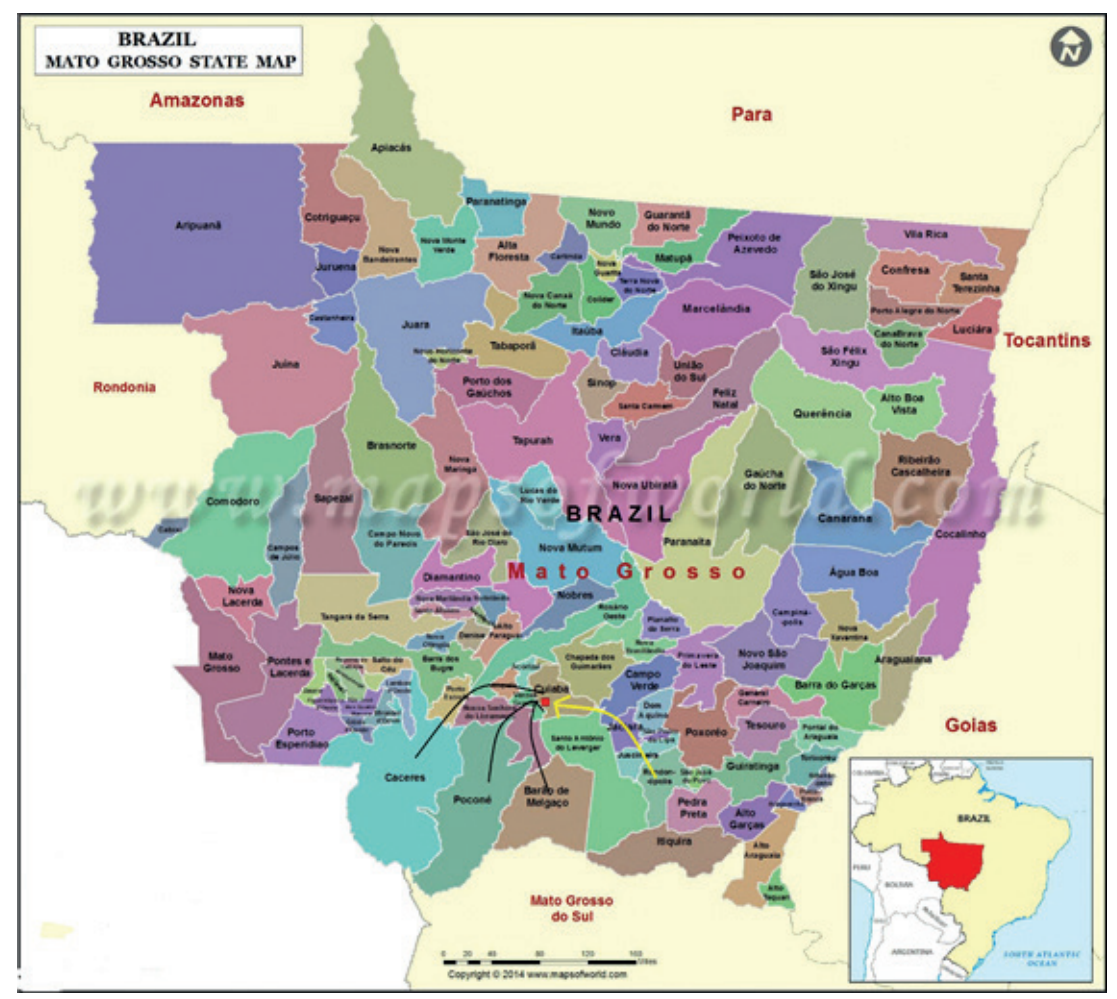

Imagem 2: Fluxos migratórios.

Alguns pequenos fluxos foram identificados durante a etnografia. As cidades mais colocadas em evidência foram Barão de Melgaço, Cáceres, Poconé e Rondonópolis. As setas em preto são as travestis que saem de cidades bem pequenas e chegam para fazer ponto na rua das bichas, e entram na base da hierarquia sendo que normalmente a dona da pensão na qual elas se alojam, é a responsável por pontos mais periféricos do Zero.

Para além desses fluxos, temos a seta amarela indica o fluxo de travestis de Rondonópolis para Cuiabá. Como Rondonópolis é uma cidade considerada grande porte por isso as travestis que migram de lá para cá, já trabalham na prostituição há algum tempo e já possuem várias modificações corporais. Por isso, quando chegam no Zero já entram com certo status e ficam na pensão responsável pelos melhores pontos, que incluem ruas mais iluminadas e asfaltadas, pontos mais perto de motéis e com maior segurança relativa.

Isso significa que as travestis que chegam do interior passam por um caminho semelhante às travestis que já são de Cuiabá e adentram pela primeira vez no mercado de trabalhadora do sexo, iniciando sua carreira e suas modificações 
corporais tal qual as "bichas" que iniciam sua jornada no Zero. Enquanto isso, as travestis que já tem certa carreira e renome (Tops ou Gatas, como são chamadas), junto do corpo próximo ao feminino, já moram em uma "boa pensão" e já adentram no Zero dentro de um status superior na hierarquia.

Os fluxos de saída do Zero, estão mais voltados para outras capitais do Brasil do que para o interior, por isso o mapa não apresenta nenhum contrafluxo para a análise de tal ponto verificar a dissertação defendida em 2019 no âmbito do PPGAS/UFMT. Mas, o que vale ressaltar é que a dona da pensão das travestis que vem do interior, também veio do interior há alguns anos, mais precisamente de Poconé. É interessante pensar também o quanto alguns marcadores da diferença se fazem presente: a dona da pensão das Tops é branca e veio de "cidade grande", enquanto a dona da pensão das bichas e travestis periféricas é negra e veio de uma "cidade interiorana". A maioria dos informantes que se referem a ela, por vezes, riem ou fazem algum tipo de brincadeira com seu sotaque do interior.

A dona da pensão que, ao mesmo tempo, oferece casa e segurança particular no Zero, acaba sendo a mesma figura que controla todo o território e que oferece certa segurança ao contratar seguranças particulares. Isso ocorre pois elas são vistas como pessoas que ajudaram elas quando mais precisavam: "A maioria é expulsa de casa e as donas de pensão abrem o coração e cuidam delas. Jamais podem ser confundidas com cafetinas. Não possuímos agenciadores algum, pois sempre trabalhamos para nós mesmas, sem nenhum tipo de mediação entre a gente e os clientes, muito menos pagamos qualquer tipo de porcentagem por usar a rua. Somos profissionais independentes", comentou Daniela para mim, num tom áspero quando perguntada sobre agenciadores.

Em comparação ao estudo de Larissa Pelúcio (2009) com travestis que se prostituem, esse ponto também foi levantado durante a sua etnografia: as donas da pensão merecem ser respeitadas pois já fizeram ponto na rua e conquistaram esse espaço. Para isso, é essencial não roubar o ponto dela, pois isso geraria violência e inclusive ameaças de morte, segundo a pesquisa de Pelúcio. Assim, indo ao encontro do que Pelúcio (2009) mostra em sua etnografia, percebemos algo bem semelhante no Zero: uma relação afetiva com a dona da pensão $0^{7}$. Todavia, existe uma linha tênue que separa justamente a afetividade da agressividade: a questão financeira. Quando ocorrem atrasos no pagamento da pensão é bem

7 Essa é uma diferença entre as pesquisas: enquanto as entrevistadas de Pelúcio (2009) usam a palavra "cafetina" para referir-se à dona da pensão, as travestis destas pesquisas jamais referem-se com essa nomenclatura e inclusive, acham ofensivo chamá-las assim. 
possível que essa figura materna, representada pela dona da pensão, vire uma potencial agressora, uma vez que as mesmas travestis que dividem a pensão estarão na rua juntas. A dona da pensão cria laços de parentesco por afinidade com as travestis, que se enxergam como irmãs.

Como foi mencionado por Agier (2011), o parentesco no contexto urbano se dá muito mais pela via de afinidades do que sanguínea. Com isso, a dona de pensão assume a figura de mãe, que ensina e educa, mesmo que por meios hostis. Por isso elas consideram a agressão das pessoas de fora da "tribo" como violência, mas das pessoas de dentro não, pois é o papel da matriarca ensinar, educar, impor limites pois se ela não o fizer, as pessoas de fora o farão e de uma maneira bem pior.

Virar dona de pensão é uma das perspectivas futuras que se encontra mais próxima das travestis tops. Dani, uma das exceções do Zero por fazer faculdade, partilha desse mesmo planejamento: "eu não penso em exercer direito, quero usar só pra causas das travestis. E o que me der dinheiro eu faço, seja no direito ou seja no Zero. No fundo todas as meninas aqui querem ser donas de pensão, $o$ maior status que se pode alcançar". E esse lugar na hierarquia só é possível de se alcançar por meio de um senso estético próprio.

Sobre o senso estético, Bourdieu (2006) explica como essa noção cria camadas que se distinguem e tornam-se hierárquicas, mesmo dentro de um grupo com estética tão singular, como neste caso são as travestis:

Assim, a disposição estética é a dimensão de uma relação distante e segura com o mundo e com os outros que pressupõe a segurança e a distância objetiva; a manifestação do sistema de disposições que produzem os condicionamentos sociais associados a uma classe particular [...] ela é também uma expressão distintiva de uma posição privilegiada no espaço social [...] como toda espécie de gosto, ela une e separa: une todos os que são produtos de condições semelhantes (Bourdieu, 2006: 56).

Essa "disposição estética" aglutina identidades e cria as camadas hierárquicas. Esses condicionamentos sociais significam uma ação condizente ao status - a dona de pensão deve ser toda transformada. A dona da pensão é a que possui mais respeitabilidade dentro da hierarquia e é a que mais se aproxima do mundo de fora, está próxima a "todos os que são produtos de condições semelhantes", participando de festas, viajando, indo desfilar no Carnaval do Rio de Janeiro, mantendo carro e posses.

Essa disposição estética separa as camadas do mundo de dentro de maneira incisiva. A dona de pensão é conhecida por todas, mas em raras vezes vai até o Zero, estando sempre no mundo de fora, compartilhando das disposições 
estéticas desse mundo. Já as travestis periféricas, em sua maioria negras são as que mais sentem a intolerância estética desde a sua entrada no Zero e todos os fatores mencionados anteriormente, reiterando o quanto "a intolerância estética exerce violências terríveis" (Bourdieu, 2006: 57).

Essa intolerância é justamente a barreira que se estabelece entre as classes, estendendo nesse caso entre as camadas da hierarquia, como se essa diferença estética fosse natural aos que se aglutinam. Bourdieu (2006) chama isso de $a b$ solutização da diferença. A tomada de posição, que inclui a cosmética corporal, somente reforça a posição do lugar social ocupado, naturalizando as relações e as posições ocupadas socialmente pelas pessoas. A intolerância estética tem o poder de barrar pessoas de assumirem certas posições sociais e a ocuparem determinados espaços. No Zero, é visível a separação e a aglutinação de identidades semelhantes por meio do senso estético, principalmente no âmbito que Bourdieu (2006) explica como "cosmética corporal".

A questão do belo é uma das características mais analisadas dentro da permissividade de uso dos espaços. As travestis belas são aquelas que possuem o corpo mais feminino e inteligível (Butler, 1993), conseguem comportar-se de maneira feminina, as roupas tendem a ser mais discretas (quando estão ocupando espaços na cidade, e não na performance do trabalho). $\mathrm{O}$ belo também está intimamente ligado a quais estados do país elas podem ir trabalhar e quais espaços do Zero elas podem ocupar, juntamente com a definição de em qual pensão poderão morar, das travestis Tops ou das periféricas interioranas.

Esse espaço ocupado por travestis negras, principalmente por essa absolutização da diferença, está sempre ligado aos lugares com menos infraestrutura, perto das bocas de fumo, longe das avenidas, em ruas de estrada de chão ou mesmo sem saída. É a parte mais vulnerável do mundo de dentro, ao contrário de uma disposição a pensar que as "bichas” que acabaram de entrar na prostituição seriam esse grupo. As "bichas" ainda moram com seus familiares, usam da prostituição para ganhar dinheiro para ir em festas e não dependem financeiramente dela para sobrevivência. Já as travestis periféricas dependem da prostituição para sobreviver e são fadadas a ocuparem espaços perigosos, moram numa pensão e em grande parte são do interior do estado.

\section{LANCLANDO MAIS QUESTÕES DE "FORA DOS CENTROS"}

Em Lopes (2016), foi apresentado Jejé de Oyá, um personagem bastante conhecido na capital cuiabana, argumentei por meio da exposição de alguns pontos da biografia dele sobre a necessidade teórico-política de se: 
[...] descortinar as possibilidades de subversão da ordem, de resistência a um discurso que aponta(va)m Cuiabá como uma "cidade do interior", conservadora, provinciana e pautada pela tradicionalidade. Estas análises buscam apontar, as ambiguidades e contradições que envolvem a vivência das sexualidades em uma cidade como Cuiabá que apesar de ser capital de estado ainda é tomada por muitos interlocutores como uma "cidade do interior" (Lopes, 2016: 35).

Naquele texto argumentei, de modo provocativo, que para estudar as sexualidades em "contextos interioranos" temos de parar de repetir a lógica e o discurso "urbanocêntrico" (Ferreira, 2006) que apontam o "interior do país" como um lócus de expulsão de pessoas com vivências diferentes da heterossexual, como um contexto sociocultural totalmente marcado por tradicionalidade e violência e passar a apostar mais na "produtividade" do que é gerado nestes distintos loci de pesquisa. Seguindo Foucault, em "Vigiar e punir" (1987: 172):

Temos que deixar de descrever sempre os efeitos de poder em termos negativos: ele "exclui", "reprime", "recalca", "censura", "abstrai", "mascara", "esconde". Na verdade, o poder produz; ele produz realidade; produz campos de objetos e rituais da verdade. O indivíduo e o conhecimento que dele se pode ter se originam nessa produção.

Assim, ao falarmos do Zero, temos de ressaltar não apenas os significados que emergem nas falas da mídia, do Estado e das Políticas Públicas que reconhecem a área como um espaço desordenado, desestruturado e cheio de violência; um espaço "marginal" presente em uma cidade do interior preconceituosa, discriminadora e violenta. Pelo contrário, as falas de nossas interlocutoras apontaram "muitas rotas de saída" dessa visão empobrecedora da realidade vivida por elas, como vimos o Zero é um espaço reconhecido nacionalmente como superestruturado, intra-hierarquizado e seguro para a vivência das atividades que giram em torno das profissionais do sexo. $\mathrm{O}$ objetivo deste artigo assim é apresentar e apostar na complexidade e "modernidade" deste local, marcado por uma diversidade de moradores e atividades e que se destaca como um espaço no qual se assentam "distintas camadas" com significações diferentes para as pessoas que por ali transitam e vivem. O Zero assim é um local extremamente sobrecodificado, apesar de ser reiteradamente apresentado pelo "discurso oficial" como um "local da desordem" social. 
Desse modo, nas pesquisas que estamos desenvolvendo aqui no Núcleo de Antropologia e Saberes Plurais (NAPlus/UFMT) ${ }^{8}$ apostamos em uma postura político-acadêmica crítica que rejeite as oposições e "modos de olhar" originados nas pesquisas realizadas nas "grandes capitais" inspirados, tal como aponta Pereira (2015) em uma teoria "queer decolonial" que pensa o queer e o decolonial como:

[...] campos abertos que se definem exatamente na medida em que afeccionam e são afetados pelos Outros. O que torna o encontro entre essas teorias provável e fecundo é que não são pensamentos fechados em si, mas movimentos de abertura para Outros, de inserção de teorias-outras e de outras formas de pensar e ser. O queer e o pensamento decolonial são campos em construção, espaço que confluem a força de corpos e geopolíticas. A diferença colonial manifesta-se nos corpos. Os corpos não são apenas corpos-tempo, mas corpos-espaço - os corpos são entranhados nos espaços [...]. Os corpos queer são constituídos na diferença, colonial. Não há como separar corpos abjetos, sexualidades dissidentes de localização geográfica, língua, história e cultura. A teoria queer é também uma política de localização - queer e pensamento decolonial são teorias corporificadas" (Pereira, 2015: 417-418).

Nesse sentido, ao falarmos dos corpos que ocupam o Zero, em especial os corpos das travestis, buscamos apontar de modo particular as relações entre espaços, fluxos, hierarquizações e intra-hierarquizações que instituem e fundamentam performances e dissidências de gênero por meio de uma visão que ressalta os agenciamentos produzidos por elas em seu cotidiano, suas táticas e estratégias de empoderamento por meio da produção de seus corpos, vínculos afetivos com a "dona da pensão", ou com a afirmação/ negação de seu local de origem.

Buscamos neste texto, mesmo que de modo conciso - uma análise "mais detida e pormenorizada" pode ser encontrada na dissertação defendida por Schuster (2019) - ressaltar as possibilidades de subversão da ordem, de resistência e simultaneamente a construção de uma "outra-ordem" que funciona em paralelo a ordem socialmente instituída e que apresenta as travestis como "exiladas nas margens", "asiladas na periferia" da sociedade. Pelo contrário, estas em seu cotidiano produzem essa "outra-ordem" no contato constante com o Estado,

8 Para mais informações sobre as atividades desenvolvidas pelo NAPlus/UFMT. Disponível em: <https:// www.naplusufmt.com/. Acesso em: 07 abr. 2020. 
trazendo-os à seu "campo de existência" e "instituindo" em 2008, mesmo que a contragosto, um "Pacto de conduta entre Profissionais do Sexo - Travestis e Agentes de Segurança Pública do Estado de Mato Grosso" mediado pelo Centro de Referência em Direitos Humanos e Prevenção e Combate a Homofobia (CRDH), que existiu entre os anos de 2008 e 2012, sendo incorporado atualmente à Secretaria de Direitos Humanos, estavam presentes alguns agentes de Segurança Pública, da Saúde, a ANTRA - Associação Nacional das travestis e a ASTRA/MT - Associação das Travestis do Estado de Mato Grosso. Foram realizadas oficinas, palestras e grupos de trabalho visando a prevenção de DSTs, tal como apontado, por Aragusuku e Lopes (2016).

Nos inspiramos também nas provocações de Fernandes e Gontijo (2016), presentes em seu manifesto "queer caboclo" na medida em que buscamos não apenas narrar as trajetórias de travestis, mas apresentar seus próprios agenciamentos, suas próprias normas, posturas, estruturas discursivas que rejeitam, por exemplo, a nomeação da "dona da pensão" como "cafetina", visto que reconhecem as práticas destas como presente no campo da "pedagogia da vida travesti" visando a "preservação da vida" e não no campo do agendamento de suas atividades de profissionais do sexo. Com isso, buscamos também:

[...] romper com o fetichismo em torno de ideias em cuja base resida a intensificação e/ou reificação dos lugares onde se produz a diferença colonial. É inegável que o pensamento auto-identificado como "ocidental" representa uma contribuição relevante para a compreensão de fenômenos sociais, mas o alcance de tal contribuição é quimérico, se levarmos em conta que junto com a ideia de ocidente há, sub-repticiamente, uma noção limitadora no tocante a outras formas de ser/estar no mundo em cuja base de compreensão se dê foral além das noções contempladas na visão de racionalidade moderna. (Fernandes; Gontijo, 2016: 20).

Finalizando, gostaríamos de destacar que mais do que dar respostas prontas e finais aos problemas apresentados o que este texto se propõe é fazer perguntas sobre as diversidades sexuais e de gênero por meio do contexto de uma "capital do interior", de um "centro fora do centro" e das biografias de sujeitos que insistem em manipular criativamente, de acordo com o contexto vivido, seus marcadores da diferença.

\section{Referências}

AGIER, Michel. Antropologia da cidade: lugares, situações e movimentos. São Paulo, Terceiro Nome, 2011. 
ARAGUSUKU, Henrique Araújo; LOPES, Moisés. Preconceito, Discriminação e Cidadania LGBT: Políticas Públicas em Mato Grosso e no Brasil. In: ACENO - Revista de antropologia do Centro-Oeste, UFMT, v. 3, n. 5, 2016, pp. 242-258.

BENEDETTI, Marcos. Toda feita. O corpo e o gênero das travestis. Rio de Janeiro, Garamond, 2005, pp. 51-88.

BOURDIEU, Pierre. A distinção: a crítica social do julgamento. 1. ed. Porto Alegre, Zouk, 2006.

BUTLER, Judith. Corpos que pesam: sobre os limites discursivos do sexo (1993). In: LOURO, Guacira Lopes. O Corpo Educado. 3. ed. Belo Horizonte, Autêntica Editora, 2016.

DAMATTA, Roberto. A casa e a rua: espaço, cidadania, mulher e morte no Brasil. 5. ed. Rio de Janeiro, Rocco, 1997.

DE CERTEAU, Michel. Terceira parte: Práticas de Espaço. In: A invenção do cotidiano, 1 artes de fazer, 3. ed. Petrópolis, Vozes, 1998, pp. 169-217.

FERNANDES, Estêvão; GONTIJO, Fabiano. Diversidade Sexual e de Gênero e Novos Descentramentos: Um manifesto Queer Caboclo. Amazônica - Revista de Antropologia, UFPA, v. 8, n. 1, 2016, pp. 14-22.

FERREIRA, Paulo Rogers. Os Afectos Mal-Ditos: o indizível das sociedades camponesas. Dissertação de Mestrado, Antropologia Social, UnB, 2006.

FOUCAULT, Michel. Vigiar e Punir: nascimento da prisão. Petrópolis, Vozes, 1987.

INGOLD, Tim. Jornada ao longo de um caminho de vida: Mapas, descobridor-caminho e navegação. Religião e Sociedade, v. 25, n. 1, 2005.

LOPES, Moisés. Algumas Observações sobre as Homossexualidades em 'Contextos Interioranos': Lançando questões de 'Fora dos Centros'. Amazônica - Revista de Antropologia, UFPA, v. 8, n. 1, 2016, pp. 24-37.

MAGNANI, José Guilherme Cantor. A antropologia Urbana e o desafio da metrópole. In: Tempo soc. São Paulo, v. 15, n. 1, 2003.

Da periferia ao centro, cá e lá: seguindo trajetos, construindo circuitos. Anuário Antropológico II, 2012.

PELÚCIO, Larissa. Abjeção e desejo: uma etnografia travesti sobre o modelo preventivo de aids. 1. Ed., São Paulo, Anablume, 2009.

PEREIRA, Pedro Paulo Gomes. Queer decolonial: quando as teorias viajam. Contemporânea - Revista de Sociologia da UFSCar, São Carlos, v. 5, n. 2, 2015, pp. 411-437.

SEDGWICK, Eve Kosofsky. A epistemologia do armário. Cadernos Pagu, Campinas, UNICAMP, n. 28, 2007, pp. 19-54.

SCHUSTER, Haydeé. A dona da rua: Territorialização e Performance de gênero a partir da prostituição de travestis na Baixada Cuiabana. Dissertação de Mestrado, Antropologia Social, UFMT, 2019. 
Recebido em: 22/12/2019

Aprovado em: 20/03/2020

\section{Como citar este artigo:}

LOPES, Moisés e SCHUSTER, Haydeé Tainá. Prostituição de travestis na Baixada Cuiabana: hierarquização, territorialização e dissidências de gênero com base em uma perspectiva (des)centrada. Contemporânea - Revista de Sociologia da UFSCar, v. 10, n. 1, jan.- abril 2020, pp. 81-100. 